\title{
Unusual skeletal muscle metastasis from carcinoma cervix
}

\author{
Mehlam Kausar ${ }^{1}$, Desh Deepak Ladia ${ }^{1}$, Abhinav Mutneja ${ }^{1}$, Virendra Bhandari² \\ ${ }^{I}$ Department of Radiation Oncology, Sri Aurobindo Institute of Medical Science, Indore 452008, Madhya Pradesh, India. \\ ${ }^{2}$ Roentgen-SAIMS Radiation Oncology Centre, Sri Aurobindo Institute of Medical Sciences, Indore 452008, Madhya Pradesh, India.
}

Correspondence to: Dr. Virendra Bhandari, Roentgen-SAIMS Radiation Oncology Centre, Sri Aurobindo Institute of Medical Sciences, Indore 452008, Madhya Pradesh, India. E-mail: virencancer@yahoo.co.in

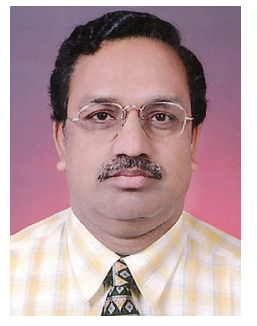

\begin{abstract}
Dr. Virendra Bhandari, MD in Radiation Oncology, has worked as Senior Registrar at TMH, Mumbai and then as Consultant Oncologist at Allahabad and Aurangabad, and treated solid and haematological malignancies. He has been trained in Brachytherapy, Hyperthermia, IGRT, SRT, and SBRT at Christie Hospital Manchester(UK), Utrecht Hospital and DD Hoed Hospital, The Netherlands, Henry Ford Hospital, Detroit \& FROG's Clinics, Jacksonville, USA and Humanitas Hospital, Milan, Italy. Presently he is working Professor at Sri Aurobindo Medical College and P G Institute, Indore. He has 35 Publications in Indexed journals to his credit.
\end{abstract}

Cervical cancer is the most common malignancy in Indian women. It usually spreads locally or via regional lymphatics to retroperitoneal lymph nodes and hematogenous spread is rare. The occurrence of skeletal muscle metastases is a very rare event and only a few cases have been reported in literature. The authors present an unusual case of cervical carcinoma in a patient that presented with skeletal muscle metastasis 1 year after the treatment.

Key words: Cervix; skeletal muscle; unusual metastasis

\section{INTRODUCTION}

Metastasis of carcinoma cervix to skeletal muscles is a rare occurrence. Muscles are highly resistant to primary and metastatic cancer due to their high contractile activity, local changes in $\mathrm{pH}$, oxygenation, accumulation of metabolites, blood flow, and local temperature. ${ }^{[1]}$ Psoas, iliopsoas, paraspinal muscles, and proximal musculature of the upper and lower limbs, represent the most frequently involved sites. Malignancies known to metastasize frequently to the muscle are melanoma, kidney, lung, thyroid cancer, lymphoma, leukemia and colon cancer. ${ }^{[2]}$ We report a case of carcinoma cervix with metastasis to paraspinal and intercostal skeletal muscle as the initial sign of dissemination.

\section{CASE REPORT}

A post-menopausal female, married for 45 years with two children, presented with a complaint of white discharge

\begin{tabular}{|l|l|}
\hline \multicolumn{3}{|c|}{ Access this article online } \\
\hline Quick Response Code: & Website: \\
& www.jcmtjournal.com \\
\cline { 2 - 3 } & \\
\hline
\end{tabular}

per vagina for 3 months. On local examination, cervix was completely destroyed by a proliferative growth involving both the right and left fornix and the lower third of the vagina. Both the right and left parametrium were indurated to the lateral pelvic wall. Ultrasonography of the abdomen was suggestive of $8.6 \mathrm{~cm} \times 5.3 \mathrm{~cm}$ large solid heterogeneous mass with scattered calcification in the cervical region. Histopathology from the growth revealed moderately differentiated squamous cell carcinoma. Metastatic workup did not show any metastatic lesion in liver or lungs. Thus, a diagnosis of carcinoma cervix IIIb (Federation of Gynecology and Obstetrics stage) was made. Then, the patient was planned for concurrent chemotherapy and radiotherapy. She was given radical radiotherapy to the whole pelvis with external beam radiotherapy to a dose of $60 \mathrm{~Gy} / 30$ over a period of 6 weeks. She also received 6 cycles of weekly cisplatin concurrently $\left(30 \mathrm{mg} / \mathrm{m}^{2}\right.$ intravenous). Intracavitary boost was not given as both the

This is an open access article distributed under the terms of the Creative Commons Attribution-NonCommercial-ShareAlike 3.0 License, which allows others to remix, tweak, and build upon the work non-commercially, as long as the author is credited and the new creations are licensed under the identical terms.

For reprints contact: service@oaepublish.com

How to cite this article: Kausar M, Ladia DD, Mutneja A, Bhandari V. Unusual skeletal muscle metastasis from carcinoma cervix. J Cancer Metastasis Treat 2016;2:67-9.

Received: 02-03-2015; Accepted: 26-10-2015. 




Figure 1: Contrast enhanced computed tomography-thorax showing skeletal muscle metastasis in the paraspinal and intercostal muscles invading the vertebra (red arrow) and lung metastasis (white arrow)

fornices were flushed, and vagina was small and conical. The patient remained locoregionally controlled for 1 year, after which she presented with complaints of swelling in the left side of the back along with pain. On examination, a large tender swelling was seen on left paraspinal region, size around $8 \mathrm{~cm} \times 4 \mathrm{~cm}$, hard and fixed. Vaginal examination performed at the time showed growth over cervix extending to involve upper $2 / 3$ of the vagina, and both the parametrium were involved. Contrast-enhanced computed tomography (CT)-thorax revealed a huge mass in the left paraspinal muscles, involving the vertebrae along with multiple lung secondaries [Figure 1]. Fine-needle aspiration cytology (FNAC) from back mass revealed metastatic squamous cell carcinoma [Figure 2]. The patient was advised for palliative local radiotherapy to vertebra followed by chemotherapy, but patient declined treatment and went home and succumbed to the disease.

\section{DISCUSSION}

The incidence of metastasis to skeletal muscles is $<1 \%$ of all hematogenous metastasis despite the fact that the muscles represent $50 \%$ of total body mass in a person. ${ }^{[2]}$ Cancer cell survival is found more in denervated muscle, which is unable to contract rather than those stimulated one. ${ }^{[3]}$

Skeletal muscle involvement from cervical cancer is very rare. ${ }^{[4]}$ Since 2008 , only 10 cases with muscle metastasis from cervical cancer have been reported in literature. Deleted the third mention of the fact that the most common site of muscle metastasis is psoas..$^{[5,6]}$ Various imaging modalities have been used to identify metastasis to muscle, but none of them are specific in differentiating carcinomas, sarcomas and other muscle disorders. CT scans show muscle metastasis as muscle enlargement but cannot specify this as malignant. Magnetic resonance imaging (MRI) in metastatic lesions show low to intermediate intensity on T1weighted images, high intensity on T2-weighted images,

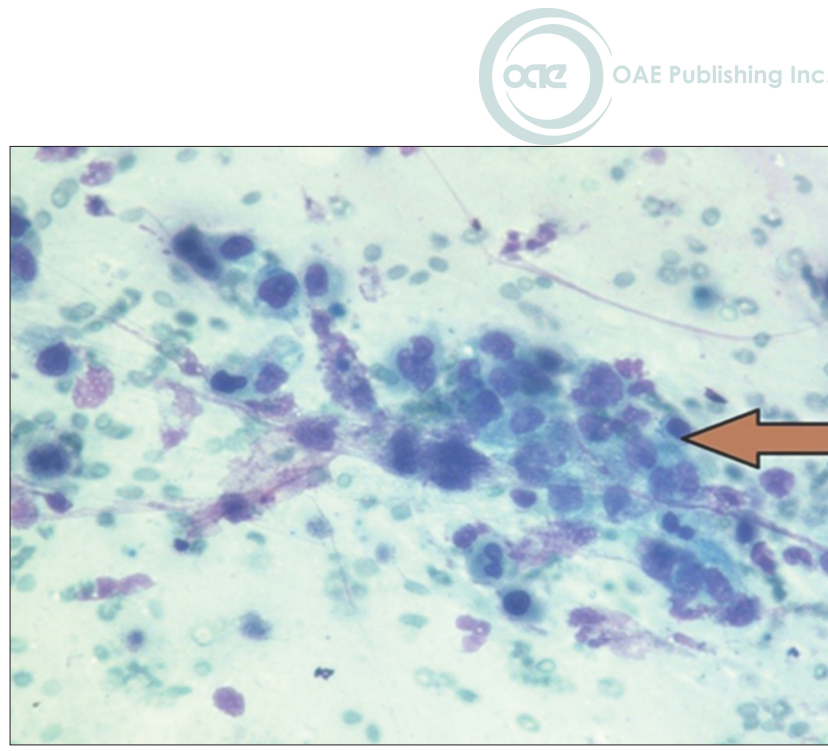

Figure 2: Fine-needle aspiration cytology from skeletal muscle mass showing nests of pleomorphic squamous cells (bold arrowhead)

and enhancement on gadolinium. ${ }^{[7]}$ Our patient declined an MRI scan. Differentiation between a primary sarcoma and metastatic carcinoma is difficult without a biopsy/FNAC ${ }^{[8]}$ The FNAC was done, which showed metastasis from squamous cell carcinoma in the muscles. Primary squamous cell carcinoma in muscle is not recognized, and thus we have concluded that this is a metastasis from the past diagnosis of cervical cancer.

The outcome of the patients with skeletal metastasis is usually poor mostly due to diffuse metastasis and a lack of consensus on treatment options. When exercised, treatment options include radiotherapy, chemotherapy, and surgery according to the site number and extension of the lesion. In the case of a solitary skeletal muscle metastasis, metastasectomy has been performed, followed by radiotherapy. ${ }^{[4]}$ The general consideration of skeletal muscle metastasis usually requires chemotherapy, in particular, the platinum-taxane combination is often chosen because of high response rate documented with this regimen as compared to cisplatin alone. ${ }^{[10]}$ Palliative radiotherapy or combined radiotherapy and chemotherapy are effective in controlling pain and size of the metastatic lesion. ${ }^{[9]}$

A reason for the prevalence (I have changed incidence to prevalence) of skeletal muscle metastasis in cervix cancer being low may be due to difficulty in differentiating malignant from benign lesions. Thus, in a patient with the previous history of cancer presenting with soft tissue mass, skeletal muscle metastasis should be considered and should be confirmed with imaging modalities and FNAC/biopsy. On confirmation palliative chemotherapy with or without local radiotherapy for pain should be given.

Muscular pain or weakness or just a palpable mass in a patient with a history of cervical cancer should always raise the suspicion of the metastatic muscular disease even after many years of locally controlled disease.

\section{Financial support and sponsorship} Nil. 


\section{Conflicts of interest}

There are no conflicts of interest.

\section{REFERENCES}

1. Acinas Garcia O, Fernandez FA, Satue EG, Buelta L, Val-Bernal JF. Metastasis of malignant neoplasms to skeletal muscle. Rev Esp Oncol 1984;31:57-67

2. Sudo A, Ogihara Y, Shiokawa Y, Fujinami S, Sekiguchi S. Intramuscular metastasis of carcinoma. Clin Orthop 1993;296:213-7.

3. Weiss L. Biomechanical destruction of cancer cells in skeletal muscle: a rate-regulator for hematogenous metastasis. Clin Exp Metastasis 1989;7:483-91

4. Ferrandina G, Salutari V, Testa A, Zannoni GF, Petrillo M, Scambia G. Recurrence in skeletal muscle from squamous cell carcinoma of the uterine cervix: a case report and review of the literature. BMC Cancer 2006;6:169.

5. Padhi S, Banerjee S, Das S, Rout N. Carcinoma cervix with atypical presentation of the metastatic lesion as a cyst in the right deltoid muscle. Indian J Pathol Microbiol 2008;51:450-1.

6. Mariya Y, Watanabe S, Yokoyama Y, Tarusawa N, Takekawa S, Kattou K, Kaimori M, Ise N. Metastasis of uterine cervical cancer to the biceps muscle of right upper arm; report of a case. Rinsho Hoshasen 1990;35:1447-50.

7. Williams JB, Youngberg RA, Bui-Mansfield LT, Pitcher JD. MR imaging of skeletal muscle metastases. AJR Am J Roentgenol 1997;168:555-7.

8. Viswanathan N, Khanna A. Skeletal muscle metastasis from malignant melanoma. Br J Plast Surg 2005;58:855-8.

9. Tuoheti Y, Okada K, Osanai T, Nishida J, Ehara S, Hashimoto M, Itoi E. Skeletal muscle metastases of carcinoma: a clinicopathological study of 12 cases. Jpn J Clin Oncol 2004;34:210-4.

10. Moore DH, Blessing JA, McQuellon RP, Thaler HT, Cella D, Benda J, Miller DS, Olt G, King S, Boggess JF, Rocereto TF. Phase III study of cisplatin with or without paclitaxel in stage IV B, recurrent or persistent squamous cell carcinoma of the cervix: a gynecologic oncology group study. J Clin Oncol 2004;22:3113-9. 